\title{
Modelling Community Participatory Systems to Improve Health Care interventions for Adolescents in Latin America
}

Kathya Lorena Cordova-Pozo ( $\sim$ kcordovapozo@gmail.com )

Universidad Privada Boliviana https://orcid.org/0000-0003-0890-8657

Arnold Hagens

Universidad Privada Boliviana

Mayira Sojo-Milano

Ministerio de Salud Publica

Nancy Auquilla

Universidad de Cuenca

Francisca Cruz

Ministerio de Salud Publica

\section{Research article}

Keywords: Participatory action research, Latin America, project assessment, community participation, GMB dynamic systems modelling.

Posted Date: June 23rd, 2020

DOl: https://doi.org/10.21203/rs.3.rs-32371/v1

License: @ (1) This work is licensed under a Creative Commons Attribution 4.0 International License. Read Full License 


\section{Abstract}

\section{Background}

Community participation is a systematic process where a group of people unites with the intention to solve a common problem. Although it is not new, every project adopts their own vision of participation which could impact differently to the outcomes of the project and may not lead to improve their original situation. The goal of this study was to model the interrelationship of Participatory Action Research (PAR) with the improvement of health that adds up to Community Development (CD) and describe the implementation in recent projects in Latin America.

\section{Methods}

The approach of this research is qualitative and intends to construct a framework that displays the relationshipbetweenPAR-CDtolater assess the implementation of seven Latin American projects. Group Model Building (GMB) and document assessment were used as methods.

\section{Results}

Adynamic system model is presented.The target variable is CD while control variables are the situation analysis, stakeholders, policy, bidirectional contribution, context-based for cultural-social-ethical, evidence-based and availability of resources. In the document assessment some missing elements were identified like dynamics of time, evidence base, cost-effectiveness, availability of resources, feasibility, replicability, sustainability, and scalability.

\section{Conclusions}

This research demonstrates that success of PAR-CD depends on a complex and dynamic system that contains causal loops and control factors. It alsoevidences the gap between an ideal model and what is implemented of PAR-CDgivingopportunities for improvement.

\section{Trial registration:}

Permission to conduct this study was granted by a research ethics committee at Colegio Medico de Cochabamba, Bolivia.

\section{Background}

Community participation is a systematic process where a group of people unites with the intention to solve a common problem (1-3). In the context of Sustainable Development Goals (SDG), participation of the community is of key importance to advance in rights, tackle some of the health determinants and to improve the provision and utilization of health services $(3,4)$. Therefore, most of these actions assume that when there is community participation, the project will automatically have support, be sustainable in time and will improve the health of the population. Moreover, the project that involves participation will achieve peoples' empowerment with skills and improved behavior. However, Rifkin (5) has proved in his paper that many of these projects were just presenting participation advocacy instead of presenting evidence of what worked to reach improvement and what the main variables or processes are that could lead from community participation to health improvement (3). Although community participation is not new, every project adopts their own vision of participation which could impact differently to the outcomes of the project and may not lead to improve their original situation (6-8).

Accordingly, the question remains what type of community participation works to reach health improvement that can add up to development? In this study, community participation is understood as a group of people that will carry out a project in their community for a period of time, guided and motivated externally by an organization that has a funded project to improve their health; therefore, with a Participatory Action Research (PAR) $(2,3,9)$. The goal of this study was to model the interrelationship of Participatory Action Research (PAR) with the improvement of health that adds up to Community Development (CD) and describe the extend of implementation in recent PAR-CD projects in Latin America. This was going to be done in two parts. First, constructing a system dynamic model that displays the ideal relation between PAR-CD. Second, assessing the level of PAR used in Latin American projects to achieve health improvement according to the constructed model. The results enhance the evidence of the relation between community participation and development to be used by project managers, implementers, project funders, and policy makers.

\section{Methods}

The approach of this research is qualitative and intends to construct a framework that displays the relationship between Participatory Action Research (PAR) and CD to assess the level of PAR used in Latin American projects to achieve health improvement. For the first objective, a system dynamics approach was used based on a consensus method named Group Model Building (GMB). GMB is part of systems thinking and is based on group discussion-sessions that help developing a system dynamics model that shows causal-relations and feedback loop 
diagrams $(10,11)$. This method reunites different stakeholders with different visions and experience in projects with PAR aiming to promote consensus in the interrelationship between the PAR-CD elements, its potential to be replicated, scale-up and sustained over time, advancing in social innovation and capacity building trying to have comparable outcomes in every project that is community embedded. In this study, the GMB consisted in three structured sessions of two hours each with stakeholders (project coordinators, data collectors, community trainers and health personnel, $n=13$ ) from five countries (Bolivia, Ecuador, Nicaragua, Cuba and Venezuela) and were assisted by a facilitator modeler. They distinguished the system components of the PAR (needs assessment, planning, implementation, monitoring and evaluation) and the causal relation between PAR and CD.

The discussion sessions were done online using Zoom video communications and the system dynamics model was sketched with Vensim simulation software. The construction and final PAR-CD model was validated by the participants in three discussion sessions based on their experience and available evidence, this means, that the discussions allowed eliciting of scientific evidence that was included in the description. Throughout the sessions, all participants reached a shared understanding of PAR-CD. In the case of Venezuela and Cuba, it was not possible to have them join the discussions due to internet constraints; instead, an interview was carried out by WhatsApp and the information was later included in the model and validated by all participants.

For the second objective, a document assessment of seven projects implemented in five different Latin American countries to measure the level of community participation based on the PAR-CD systems dynamic model developed by GMB. An invitation was sent among a Latin American network of health professionals to send project protocols and other methods documents to be reviewed for community participation. The criteria for inclusion were based on funded research projects that included community participation for adolescents with the aim of improving their health. Mainly grey literature was assessed (reports and project documents) as there was little or no scientific publications on these interventions.

Both sources explain the relationship between PAR and CD or health improvement. Permission to conduct this study was granted by a research ethics committee at Colegio Medico de Cochabamba, Bolivia. Informed consent was formally requested to all informants before the discussion sessions of GMB.

\section{Results}

With the results of the group discussion sessions a general model was constructed that shows the relation of PAR and CD (Fig. 1). Figure 1 shows the causal relations, feedback loops, control, and target variables for the PAR-CD relation. For example, if you have a good quality of planning and implementation, there will be a higher involvement of the community. Figure 1 demonstrates that the success of PAR-CD depends on control variables (critical factors) such as policy, community knowledge, context based for cultural-social, ethical, available resources, definition of the outcome indicators, common goals, and diversity of stakeholders. These components can be influenced and considered in the design of the project.

Source: GMB sessions

Table 1 displays the detailed results of the document assessment compared with the system dynamic model PAR-CD. The numbers reflect the gaps in each phase (1 bad or non-addressed, 2 addressed very basic, 3 fully addressed). Principles of existence does quite well with an average value of 2.46 and a standard deviation of 0.84 shows a reasonable parity between the model and what was implemented. Table 1 shows that the three phases of a project that should include participation of a diversity of stakeholders have an average of 1.70 and the standard deviation of 0.90 reflecting a high discrepancy of what was implemented or considered in the project and the GMB model. Some missing elements that highlight these gaps in the documents are dynamics of time, evidence base, cost-effectiveness, availability of resources, feasibility, replicability, sustainability, and scalability.

\section{Table 1. Document assessment of seven case-studies for measuring the level of community participation}

\section{Note}

The projects were assessed in a Likert scale going from 1 to 3 . Being 1 bad or non-addressed, 2 being addressed very basic, 3 fully addressed.

Source: Own elaboration based on project documents assessment

\section{Principles of existence}

GMB sessions highlighted these principles as not all projects involve a participatory process. These guide the entire project, gain accountability and a stronger participation (table 1). Principles of empowerment, knowledge transfer, equity, sustainability, leadership, and Country's policy (1, $7,12)$ guide a project. Moreover, a diversity of significant actors of the community or stakeholders need to participate for accountability, 
including local authorities (municipality, health, education), community leaders, medical practitioners, organizations and local business members and others. And this provides a wider vision of the project process (12-15). Document assessment showed that few included a diversity of stakeholders, the rest included the target population only.

Theory of change (ToC) or improved behavior is a key part of promotion and prevention projects regarding health (14, 16, 17) and leads to CD. However, project document revision showed that most of the projects did not have an explicit ToC although the community movement clearly intended to improve health for adolescents.

\section{Needs Assessment}

The discussion group mentioned that a situation analysis (quantitative and qualitative approach) of the community is important to know the problems, the protective factors, and its long-term plans. Some Latin American countries do not have accessible or detailed enough statistics to observe these aspects; therefore, a longitudinal cross-sectional survey is important to assess this $(1,2)$. The participation of a trained facilitator is key to bringing the different stakeholders from the community together $(2,18)$ engaging them under the premises of a common goal, leadership, and authority endorsement $(2,18)$.

An important feedback loop is the dynamics of time for involving different actors (12-15): 1) present, the process needs to be adapted to the current external factors (PESTEL) and address the existing crucial threats, 2) projection, the furthest away in time the problem is, the more difficult it is to imagine a threat; hence, more complicated to engage the population today, 3) uncertainty, it is difficult to imagine the consequences of a non-take action now when the consequences are only visible in a few number of persons or in the future generation. These three characteristics play a strong role in the process of decision-making. It is also important to consider the cognitive bias for engaging or not in the community actions. For instance, positivism is the idea that "the problem will not reach me", the bystander "it is better that someone else works for the solution", or fixating "staying in the same situation is easier" (19).

Project document revision showed that needs assessment was mainly based on simple statistics (basic) while others were based on a crosssectional survey that later was used to evaluate the change (t0 and $\mathrm{t} 1$ ). None of the projects elicited dynamics of time. And some did not include a diversity of stakeholders for the need's assessment (table 1).

\section{Planning and Implementation}

The discussion group mentioned that planning is an important phase to list the interventions. This because communities may not be pleased with activities that do not fit their socio-cultural acceptance or are ineffective for their context. Hence, it was suggested to work thinking "with the community, from the community and for the community" in order to improve health and development (20). The project can include a bidirectional contribution where the community can inform about their natural practices and science can inform on better ways to do (theory informing practice -evidence based, and practice informing theory -experimental practice). This twofold approach is valuable for lessening the limitations of the implementation plan.

Planning has five inputs: 1) the report of the needs' assessment that includes a robust ToC and goals tailored for this report, 2) bidirectional contribution that includes community knowledge, 3) activities that are contextualized for cultural-social and ethical that supports validation, 4) evidence based that supports effectiveness, 5) available resources. The facilitator can extract in the group discussion a common vision of the problem, the explicit and implicit knowledge, values, fears, social cohesion or conflicts, perspectives, financial power, etc.

The group agreed that activities of intervention should consequently be, preferable, evidence-based and work in connection with the objectives. This means, that the activities need to be controlled by their contribution to the desired outcome (ToC) in a reliable way. In addition, it was mentioned the importance to check if each activity chosen adjusts to characteristics of the community, if it is cost-effective, and if the community would have all the resources needed for its implementation $(12,21)$. "To maintain efficiency, the ideal way it is to look for effective interventions that proved to work, then adapt these interventions to the specific community. This adaption could be a part of the implementation research process" (GMB participant).

Document review shows that not all prioritize activities according to a bidirectional contribution, or socio-cultural base. Some projects have actions not based on evidence, ethics, cost-effectiveness, or resources oriented (table 1).

\section{Monitoring and Evaluation (M\&E)}

To keep accountability, several control points can be planned for each activity (output indicators) to observe if activities are accepted or need to be replaced to reach the expected results which is called effectiveness and validation of strategies. Monitoring the advancement and behavioral change needs to be dynamic and multidimensional, this means, evaluating not only the target population but its surroundings and supporting actors. If health centers, schools, community, authorities are changing into an enabling environment, the intervention is leading to a 
community development. Aspects that show causal loops towards change may include intermediate results (outputs) and final results (outcomes) $(2,4,20)$ and dissemination of partial and final results have to be constant.

It was mentioned that vague indicators like improvement of health or happy patients are not easy to measure and the community may not know how to collect this information without bias. For instance, the indicator of high teen pregnancies is difficult to attribute to a project, thus it is better the number of students that go to the consultancy room installed by the project, number of workshops done per classroom, etc. Also, it was noted that cost-effectiveness is critical for feasibility, replicability, sustainability, and scalability. And the participation of stakeholders can help to have better estimate of the cost-effectiveness and this helps prioritization of strategies to implement, etc.

Document revision showed that aspects like clear indicators measured dynamically and multidimensionally, periodical dissemination, feasibility, replicability, sustainability, and scalability are missing in the projects (Table 1).

\section{Discussion}

Participation has advantages and is key to reach development, but it remains unclear to what level it needs to be implemented and what are the variables or processes that could lead from community participation to health improvement as mentioned by Rifkin (5). This study demonstrates that success of PAR-CD depends on a complex and dynamic system that contains causal loops, target, and control variables and shows the main gaps in the implemented projects. To our knowledge, this study is the first to display the control variables to include in the design of the project (Fig. 1) and the elements that are not included in the project (table 1) that could endanger the final outcome.

A comparison between the ideal model developed with GMB and the document assessment of the implemented projects shows gaps in several elements. The missing elements for all the countries provide an opportunity to improve participation. Dynamics of time is important to attract and engage a diversity of stakeholders eliciting the present, projection and uncertainty of time of the people involved. Unfortunately, there was no other author that cites a similar aspect. Another element to include is the evidence-based implementation action-package that proved to work and could be adapted in the new setting. This is recently backed-up from the World Health Organizations for projects of sexual and reproductive health with adolescents $(16,22)$. Other missing elements are interrelated like cost-effectiveness, availability of resources, feasibility, replicability, sustainability, and scalability. If interventions are planned with participation and thinking about bringing change, it is important to consider the availability of resources (financial, time and human). Activities should also consider cost-effectiveness including the viability to be replicated, enlarged to other regions and be sustainable. This goes in line with Cordova-Pozo and Ivanova that present some of these elements $(20,23)$ and Hainsworth and Brunton that talk about sustainability and scale-up of interventions $(15,17)$. According to the ideal PAR-CD model, the control variables that should be included in the project are a diversity of stakeholders, a situation analysis that is the base for the actions and a bidirectional contribution based on community knowledge, adapted to the social-cultural situation and based on scientific evidence and ethical approach. The consideration of these elements can increase the success of the project process and of the achievement of community development.

The study was limited to collect all the variables that could influence the PAR-CD from a qualitative and shared perspective. It is possible that group pressure may have pushed people to agree without opposition. Second, the documents assessed may not contain all details of the project procedure and it may have influenced the results and analysis. Future research may focus in quantifying the elements of the model to better estimate effects and impacts. Aspects such as: Do we talk about a few hours per month or per week? What are the tasks the community receives in the intervention? How good they implement the project guidelines or how far they can define the interventions?

\section{Conclusion}

This research has demonstrated that part of the success of PAR-CD depends on a complex and dynamic system that contains causal loops and control variables like situation analysis, stakeholders, policy, availability of resources, bidirectional contribution that includes community knowledge, context-based for cultural-social-ethical that provides validity, and evidence based that delivers effectiveness. It also indicates the gaps between an ideal model and what is implemented. Missing key elements could endanger the outcome of achieving health improvement. The results enhance the evidence of the relation between community participation and development to be used by project managers, implementers, project funders, and policy makers.

\section{Abbreviations}

CD

Community development

GMB

Group Model Building 
ToC

Theory of change

M\&E

Monitoring and evaluation

\section{Declarations}

\section{Ethics approval and consent to participate}

\section{Consent for publication}

\section{Availability of data and materials}

The datasets used and/or analyzed during the current study are available from the corresponding author on reasonable request.

\section{Competing interests}

"The authors declare that they have no competing interests"

\section{Funding}

There was no funding for this research

\section{Authors' contributions}

KCP conceived the idea and drafted the first version. AH collaborated with the facilitation of the GMB session and the document assessment. MSM, NA, FC collaborated with the organization of the GMB sessions, read and gave feedback in every version. All authors read and approved the version for submission.

\section{Acknowledgements}

We are thankful to all 13 participants of the GMB session from Bolivia, Ecuador, Nicaragua, Cuba, and Venezuela for their valuable ideas.

\section{References}

1. Theobald S, Brandes N, Gyapong M, El-Saharty S, Proctor E, Diaz T, et al. Implementation research: new imperatives and opportunities in global health. Lancet. 2018;392(10160):2214-28.

2. Decat P, Nelson E, De Meyer S, Jaruseviciene L, Orozco M, Segura Z, et al. Community embedded reproductive health interventions for adolescents in Latin America: Development and evaluation of a complex multi-centre intervention. BMC Public Health. 2013;13(1):31.

3. Marston C, Hinton R, Kean S, Baral S, Ahuja A, Costello A, et al. Community participation for transformative action on women's, children's and adolescents' health. Bull World Health Organ. 2016 May;94(5)(1):376-82.

4. Alhassan RK, Nketiah-Amponsah E, Ayanore MA, Afaya A, Salia SM, Milipaak J, et al. Impact of a bottom-up community engagement intervention on maternal and child health services utilization in Ghana: A cluster randomised trial. BMC Public Health. 2019 Jun 21;19(1).

5. Rifkin SB. Examining the links between community participation and health outcomes: A review of the literature. Vol. 29, Health Policy and Planning. Oxford University Press; 2014. p. ii98-106.

6. De Weger E, Van Vooren N, Luijkx KG, Baan CA, Drewes HW. Achieving successful community engagement: A rapid realist review. Vol. 18, BMC Health Services Research. BioMed Central Ltd.; 2018.

7. Baatiema L, Skovdal M, Rifkin S, Campbell C. Assessing participation in a community-based health planning and services programme in Ghana. BMC Health Serv Res. 2013;13(1). 
8. Cordova-Pozo KL, Cordova-Pozo G, Monza A, Píriz G, Moreno-Lopez D, Cardenas I. Derechos sexuales y reproductivos para la anticoncepción en Bolivia, Colombia y Uruguay en el marco de los derechos humanos. Rev Panam Salud Pública. 2017;41:1.

9. 10.1111/j.1540-4560.1946.tb02295.x

Lewin K. Action Research and Minority Problems. J Soc Issues [Internet]. 1946 Nov 1 [cited 2020 Mar 25];2(4):34-46. Available from: http://doi.wiley.com/10.1111/j.1540-4560.1946.tb02295.x.

10. Rouwette E, Bleijenbergh I, Vennix J. Group Model-Building to Support Public Policy: Addressing a Conflicted Situation in a Problem Neighbourhood. Syst Res Behav Sci. 2016;33(1):64-78.

11. Franco LA, Rouwette A. Messy problems - Reader. 2015.

12. $10.3389 /$ fvets.2018.00303/full

Duboz R, Echaubard P, Promburom P, Kilvington M, Ross H, Allen W, et al. Systems Thinking in Practice: Participatory Modeling as a Foundation for Integrated Approaches to Health. Front Vet Sci [Internet]. 2018 Dec 17 [cited 2020 Mar 19];5(NOV):303. Available from: https://www.frontiersin.org/article/10.3389/fvets.2018.00303/full.

13. McEvoy R, Tierney E, MacFarlane A. "Participation is integral": Understanding the levers and barriers to the implementation of community participation in primary healthcare: A qualitative study using normalisation process theory. BMC Health Serv Res. 2019 Jul 23;19(1).

14. Han H, Gabriel KP, Kohl HW. Application of the transtheoretical model to sedentary behaviors and its association with physical activity status. PLoS One. 2017 Apr 1;12(4).

15. BMC Public Health

10.1186/s12889-017-4958-4

Brunton G, Thomas J, O'Mara-Eves A, Jamal F, Oliver S, Kavanagh J. Narratives of community engagement: A systematic review-derived conceptual framework for public health interventions [Internet]. Vol. 17, BMC Public Health. BioMed Central Ltd.; 2017 [cited 2020 Mar 18]. p. 944. Available from: https://bmcpublichealth.biomedcentral.com/articles/10.1186/s12889-017-4958-4.

16. Cordova-Pozo K, Chandra-Mouli V, Decat P, Nelson E, De Meyer S, Jaruseviciene L, et al. Improving adolescent sexual and reproductive health in Latin America: Reflections from an International Congress. Vol. 12, Reproductive Health. BioMed Central Ltd.; 2015. p. 11.

17. Hainsworth G, Engel DMC, Simon C, Rahimtoola M, Ghiron LJ. Scale-up of adolescent contraceptive services: Lessons from a 5-country comparative analysis. J Acquir Immune Defic Syndr. 2014 Jul 1;66(SUPPL. 2):S200.

18. den Broeder L, Uiters E, ten Have W, Wagemakers A, Schuit AJ. Community participation in Health Impact Assessment. A scoping review of the literature. Vol. 66, Environmental Impact Assessment Review. Elsevier Inc.; 2017. p. 33-42.

19. Valdez A, Ziefle M, Sedlmair M. A Framework for Studying Biases in Visualization Research. VIS 2017 Deal with Cogn Biases Vis [Internet]. 2017 [cited 2020 Mar 30]; Available from: http://eprints.cs.univie.ac.at/5258/1/calero-valdez2017framework.pdf.

20. 10.1186/s12978-018-0461-3

Cordova-Pozo K, Hoopes AJ, Cordova F, Vega B, Segura Z, Hagens A. Applying the results based management framework to the CERCA multi-component project in adolescent sexual and reproductive health: A retrospective analysis. Reprod Health [Internet]. 2018 Feb 8 [cited 2020 Mar 16];15(1):24. Available from: https://reproductive-health-journal.biomedcentral.com/articles/10.1186/s12978-018-0461-3.

21. Decat P, De Meyer S, Jaruseviciene L, Orozco M, Ibarra M, Segura Z, et al. Sexual onset and contraceptive use among adolescents from poor neighbourhoods in Managua, Nicaragua. Eur J Contracept Reprod Heal Care. 2015 Apr 1;20(2):88-100.

22. Chandra-Mouli V, Lane C, Wong S. What Does Not Work in Adolescent Sexual and Reproductive Health: A Review of Evidence on Interventions Commonly Accepted as Best Practices [Internet]. [cited 2020 May 10]. Available from: www.ghspjournal.org.

23. Ivanova O, Cordova-Pozo K, Segura ZE, Vega B, Chandra-Mouli V, Hindin MJ, et al. Lessons learnt from the CERCA Project, a multicomponent intervention to promote adolescent sexual and reproductive health in three Latin America countries: a qualitative post-hoc evaluation. Eval Program Plann [Internet]. 2016 Oct 1 [cited 2020 Mar 16];58:98-105. Available from: https://linkinghub.elsevier.com/retrieve/pii/S0149718915300719.

\section{Tables}


Table 1

Document assessment of seven case-studies for measuring the level of community participation

\begin{tabular}{|c|c|c|c|c|c|c|c|c|c|c|}
\hline \multirow[b]{2}{*}{$\begin{array}{l}\text { Project } \\
\text { Phase }\end{array}$} & \multirow{2}{*}{$\begin{array}{l}\text { Community } \\
\text { Participationelements }\end{array}$} & \multicolumn{4}{|c|}{ Sexualandreproductive health } & \multicolumn{2}{|c|}{ Healthy lifestyles } & \multirow{2}{*}{$\begin{array}{l}\text { Malaria } \\
\text { Venezuela }\end{array}$} & \multirow[t]{2}{*}{ Average } & \multirow{2}{*}{$\begin{array}{l}\text { Standard } \\
\text { Deviation }\end{array}$} \\
\hline & & Bolivia & Ecuador & Nicaragua & Cuba & Bolivia & Ecuador & & & \\
\hline \multicolumn{9}{|c|}{ Principles of Existence } & 2.46 & 0.84 \\
\hline & Health Improvement & 3 & 3 & 3 & 3 & 3 & 3 & 3 & 3.0 & - \\
\hline & $\begin{array}{l}\text { Diversity of Stakeholder } \\
\text { involvement }\end{array}$ & 3 & 3 & 3 & 1 & 3 & 1 & 1 & 2.1 & 1.1 \\
\hline & $\begin{array}{l}\text { Theory of change as a } \\
\text { driver }\end{array}$ & 2 & 2 & 2 & 1 & 3 & 1 & 1 & 1.7 & 0.8 \\
\hline & Accountability & 3 & 3 & 3 & 3 & 3 & 3 & 3 & 3.0 & - \\
\hline \multicolumn{9}{|c|}{$\begin{array}{l}\text { Needs assessment with the } \\
\text { participation of a diversity of } \\
\text { stakeholders: }\end{array}$} & 1.71 & 0.91 \\
\hline & Situation analysis & 3 & 3 & 3 & 2 & 3 & 1 & 2 & 2.4 & 0.8 \\
\hline & Dynamics of time & 1 & 1 & 1 & 1 & 1 & 1 & 1 & 1.0 & - \\
\hline \multicolumn{9}{|c|}{$\begin{array}{l}\text { Planning and implementation with } \\
\text { the participation of a diversity of } \\
\text { stakeholders: }\end{array}$} & 1.73 & 0.88 \\
\hline & $\begin{array}{l}\text { Biderectional } \\
\text { contribution based on } \\
\text { Community knowledge }\end{array}$ & 2 & 2 & 2 & 1 & 3 & 1 & 1 & 1.7 & 0.8 \\
\hline & Social base & 3 & 3 & 3 & 2 & 3 & 3 & 2 & 2.7 & 0.5 \\
\hline & Cultural base & 2 & 2 & 2 & 3 & 3 & 3 & 3 & 2.6 & 0.5 \\
\hline & Ethical base & 3 & 3 & 3 & 1 & 3 & 1 & 1 & 2.1 & 1.1 \\
\hline & Evidence-base & 1 & 1 & 1 & 1 & 1 & 1 & 1 & 1.0 & - \\
\hline & Cost-effectiveness & 1 & 1 & 1 & 1 & 1 & 1 & 1 & 1.0 & - \\
\hline & $\begin{array}{l}\text { Availability of } \\
\text { Resources }\end{array}$ & 1 & 1 & 1 & 1 & 1 & 1 & 1 & 1.0 & - \\
\hline \multicolumn{9}{|c|}{$\begin{array}{l}\text { Monitoring and evaluation with } \\
\text { the participation of a diversity of } \\
\text { stakeholders: }\end{array}$} & 1.68 & 0.96 \\
\hline & Outputs indicators & 1 & 1 & 1 & 1 & 3 & 1 & 1 & 1.3 & 0.8 \\
\hline & Periodicaldissemination & 3 & 3 & 3 & 1 & 3 & 1 & 1 & 2.1 & 1.1 \\
\hline & Outcome indicators & 3 & 3 & 3 & 3 & 3 & 3 & 3 & 3.0 & - \\
\hline & Finaldissemination & 3 & 3 & 3 & 3 & 3 & 3 & 3 & 3.0 & - \\
\hline & Feasibility & 1 & 1 & 1 & 1 & 1 & 1 & 1 & 1.0 & - \\
\hline & Replicability & 1 & 1 & 1 & 1 & 1 & 1 & 1 & 1.0 & - \\
\hline & Sustainability & 1 & 1 & 1 & 1 & 1 & 1 & 1 & 1.0 & - \\
\hline & Scalability & 1 & 1 & 1 & 1 & 1 & 1 & 1 & 1.0 & - \\
\hline
\end{tabular}

\section{Figures}




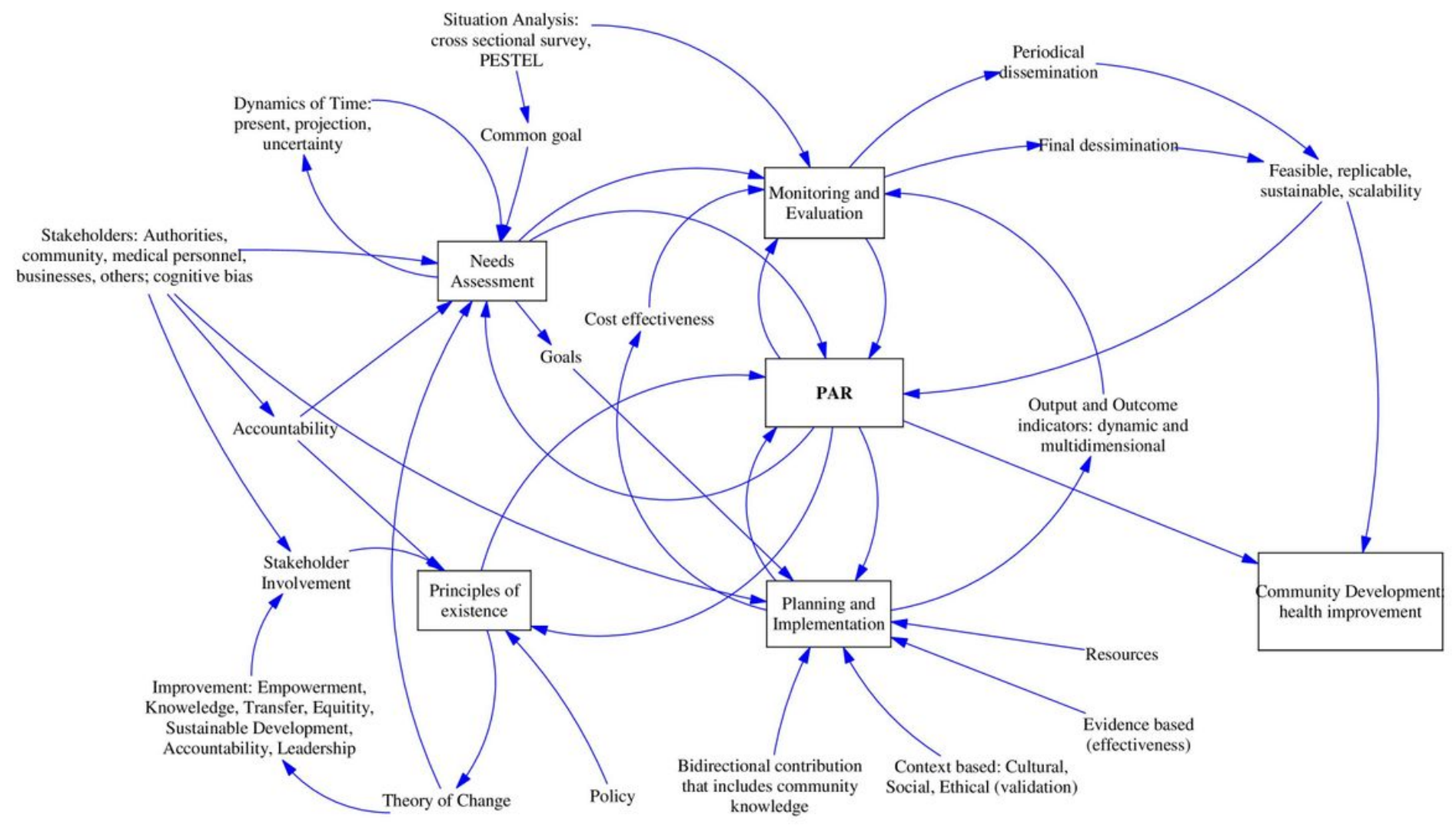

Figure 1

Ideal model that relates the PAR to $C D$ 